\title{
ANÁlISE DA TRADUÇÃO DE DOM CASMURRO PARA O ALEMÃO À LUZ DAS TEORIAS DE TOROP
}

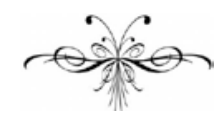

SIGFRID FRÖMMING

Resumo: Peeter Torop, estudioso da tradutologia em Tartu, Estônia, afirma haver 5 tipos de tradução: textual (clássica), metatextual (resultado e processo da tradução), intertextual (entre dois textos), intratextual (no mesmo texto) e extratextual (elementos externos ao texto). Classificou as traduções em oito categorias, alegando que toda tradução pode ser total, dentro de seus propósitos. Priorizando o original, pode-se enfatizar o macroestilo do texto, a precisão (palavra por palavra), o tema ou a descrição (conteúdo); priorizando a tradução, podese enfatizar o microestilo do autor, a literalidade do texto, a expressão imaginada no original ou a liberdade (adaptação). Ancorado nisso, abordo a tradução de Dom Casmurro para o alemão por Harry Kaufmann, identificando a estratégia selecionada. Duas delas são detectadas: a recodificação analítica dominante macroestilística (predomina o macroestilo do texto original); e a transposição sintética dominante expressiva (mesma expressão causada no leitor do original). Analiso ainda a traduzibilidade da cultura, segundo Torop: língua, tempo, espaço, obra, texto e manipulação sociopolítica. Conclui-se que o tradutor procurou manter as características principais da obra referente ao tempo, espaço e marcas culturais, porém interveio em diversos pontos do texto, deixando-o mais fluido e

\begin{abstract}
Peeter Torop, a researcher of translation studies at Tartu, Estônia, describes 5 kinds of translation: textual (classic), metatextual (result and also process of translation), intertextual (between two texts), intratextual (in the same text) and extratextual (with outside elements of the text). He says the purpose enables all translation to be total. Source text as priority can emphaticize macrostyle, precision (word by word), theme or description; target text as priority can choose author's microstyle, literality of the text, expression imagined or total liberty (adaptation). I analyze Harry Kaufmann's translation of Dom Casmurro to German, and the strategy chosen by him. Two categories can be found: macroestilistic dominant analytic recodification (the main point is the macrostyle of the source text) and the expressive dominant synthetic transposition (looks the expression the text caused upon the reader of the source text). I also analyze the translatability of the culture, according to Torop: language, time, space, work, text and sociopolitical manipulation. In conclusion the translator keeped the main characteristics of the work regarding to time, space and cultural references. However, he changed some parts with some explanations for better readability, causing a soft, but visible manipulation of the target text.
\end{abstract}


explicativo, produzindo uma manipulação sociopolítica perceptível ao longo do texto.

Palavras-chave: Peeter Torop; Tradução total; Dom Casmurro; Traduzibilidade da cultura.
Keywords: Key words: Peeter Torop. Total translation. Dom Casmurro. Cultural translatability.

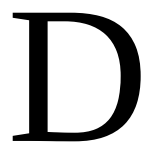

e um modo

geral, as

traduções cos

ostumam ocorrer de uma cultura/língua dominante para uma cultura de minoria, onde adquirem a visibilidade. Como exemplo dessa dominação, cita-se o Western Translation Theory: from Herodotus to Nietzsche, onde aparecem 124 textos, dos quais 119 são de 5 línguas: latim, grego antigo, inglês, francês e alemão (CRONIN, 2010, p. 250). Aplicado às línguas atuais, podemos inferir que apenas três dominam a área da tradução: inglês, francês e alemão. O perigo de se ter uma cultura dominante reside no fato de ela ocupar o espaço, eliminando as fronteiras, as diferenças. Geralmente, a cultura que se sente inferior tende a copiar, a imitar, a fazerse igual. É o que provoca a incorporação de palavras estrangeiras ao cotidiano, mesmo havendo uma correspondente na língua.

A língua alemã costuma fornecer material para ser traduzido em português. Contudo, o inverso também ocorre entre essas línguas. Ao versar sobre uma tradução do português para o alemão, é necessário considerar as culturas envolvidas. O Brasil recebeu muitos imigrantes alemães ainda antes de Machado de Assis escrever Dom Casmurro. O Rio de Janeiro, como capital do Império, e suas imediações receberam inúmeros desses imigrantes iniciais, por interesse do imperador Dom Pedro II. Com o tempo, outros se alojaram em diversos estados brasileiros, como São Paulo, Espírito Santo, Santa Catarina, Paraná, Rio Grande do Sul, onde fundaram vilas e cidades nas quais continuaram sua cultura.

Num processo de tradução, não ocorre apenas a passagem de um texto de uma língua para outra, mas também de uma cultura para outra. Teoricamente, ambas as culturas têm a mesma importância em seu contexto, cada qual em seu estágio de desenvolvimento aleatório. Porém, como diz Laraia (2001, p. 80), “a participação do indivíduo em sua cultura é sempre limitada; nenhuma pessoa é capaz de participar de todos os elementos de sua cultura”. Para o tradutor, isso significa participar de duas culturas de forma limitada, geralmente em níveis distintos. Por isso, conforme Laraia (2001), pede-se que o indivíduo tenha ao menos um conhecimento mínimo de operação dentro da cultura, a ser compartilhado com outros elementos envolvidos em tal sociedade, permitindo a convivência dos mesmos (p. 82-83).

Por analogia, podemos dizer que ao tradutor compete ter domínio mínimo nos dois sistemas culturais em que trabalha. Não sendo o domínio total, significa lidar com retalhos, recortes culturais ao nível pessoal. O material original já nasce fracionado pelo autor, e está predestinado a sofrer um recorte cultural ainda maior pelo tradutor. Mas mesmo os "fragmentos" possuem um vínculo com aquilo que o circunda. Não há texto isolado no espaço cultural, o que abre caminho para sempre ocorrerem novas traduções. Semelhantemente Baker (2010) fala dos conhecimentos sobre a constituição das narrativas: dentro de um momento temporal, num espaço físico, os humanos sempre relacionam eventos com outros anteriores que constituem 
uma narrativa, não sendo possível isolar por completo um fato; certos critérios fazem a seleção dos fatos considerados importantes ou descartáveis para a narrativa, produzindo assim um enredo independente que sobrepuja a ordem cronológica e categórica (p. 118). De modo semelhante, os critérios adotados pelo tradutor determinam a confecção de um novo texto.

No presente artigo, abordo justamente esses critérios e escolhas da tradução de Dom Casmurro para o alemão, comparando-o com as teorias descritivas de Peeter Torop, a fim de verificar em qual das oito categorias toropianas se encaixa a tradução. Confrontando a tradução com a descrição, procuro os elementos que caracterizem cada categoria, até encontrar a que mais se enquadre. No momento seguinte, observo os parâmetros da traduzibilidade da cultura listados por Torop, procurando detectar as escolhas feitas por Harry Kaufmann, o tradutor alemão.

\section{Cultura alemã e brasileira}

Nessa questão envolvendo culturas e identidades, Venuti (2005) mostra que toda identidade nacional é juntamente um discurso particular de nação e um grupo social que ativa um processo de identificação nas instituições sociais designadas a reproduzir a cultura nacional e o estado-nação. Mesmo assim são heterogêneos, pois um estrangeiro também pode obter cidadania, contribuindo com seus valores. A tradução molda a identidade nacional através da seleção de textos estrangeiros e do desenvolvimento de estratégias discursivas para traduzi-los (p. 179-180).

No caso do Brasil, a cultura dos imigrantes influenciou a que existia aqui. Em certo sentido, uma tradução feita a partir do português do Brasil poderá apresentar traços da cultura alemã “original”, uma espécie de eco cultural. A cultura brasileira, enquanto representante da nação, não tem sido homogênea, nem mesmo no universo indígena que existia antes da colonização europeia. Muitos povos contribuíram na formação, resultando em culturas localizadas.

Por isso, parafraseando Pavis (2008), além das palavras de um texto, a tradução intercultural pode usar outros elementos acessíveis aos cinco sentidos, a fim de mostrar as ligações e diferenças perceptíveis. Esse gesto não é limitado a uma função sócio-política, porém tem dimensão etnológica e simbólica, uma vez que reúne essências de culturas diferentes, como é o caso dos imigrantes (p. 150).

\section{A tradução total de Dom Casmurro}

Dom Casmurro é uma obra que traz a genialidade de Machado de Assis expressa em cada linha. Porém, para um leitor preocupado apenas com o entretenimento que uma leitura fluida poderia ofertar, tais virtudes podem passar despercebidas. Devido à transformação cultural causada pela sucessão do tempo, inúmeras passagens revelam a distância de sua origem, causando um estranhamento ao próprio leitor brasileiro. São expressões, vocabulários, costumes que se perderam no transcurso das estações. Uma análise acurada de Dom Casmurro nos revela, porém, que Machado de Assis usou uma linguagem popular, marca diluída pelo tempo, ${ }^{1}$ pois após 1883 seus contos são mais realistas, retratando as classes mais pobres, e são ambientados no Rio de Janeiro (GLEDSON, 2012, p. 20).

\footnotetext{
${ }^{1}$ Depreendido de Laraia, 2001, pp. 94-101.
} 
Em 1980, Harry Kaufmann traduziu a obra para o alemão. Como vimos, toda tradução serve a um propósito e tem seus critérios de seleção do que seja importante, e toda escolha está centrada em um objetivo determinado, quer seja pelo tradutor, quer pela editora ou outro elemento de interferência no processo. Para analisar mais detalhadamente essas questões, atenho-me a um teórico estoniano: Peeter Torop, um estudioso da tradutologia da Escola de Tartu, na Estônia, que lançou um livro em 1995 com o título Total'nyj perevod, ou seja, “Tradução total”. Nele aparecem não as teorias prescritivas da tradução, mas os aspectos descritivos. Com base em traduções feitas ao redor do mundo, Torop afirma que há 5 tipos de tradução: a textual (forma tradicional de tradução, em que um texto em uma língua vira outro texto em outra língua), a metatextual (é tanto o resultado de uma tradução como também o processo da tradução em si, pois ocorre a transferência de um texto de uma língua e cultura com todos os seus textos escritos e falados que ajudam a identificar essa cultura - para outra língua e cultura), a intertextual (ocorre entre dois textos, pois todo contexto está inserido em outro contexto com o qual se relaciona), a intratextual (dentro do mesmo texto, e reflete o estilo particular do escritor, ou seja, outros textos do mesmo escritor, uma citação de si mesmo) e a extratextual (com elementos externos ao texto, tradução semiótica, ocorrendo entre texto verbal e não-verbal, por exemplo) (OSIMO, 2004, 17-20; ${ }^{2}$ TOROP, 2000; ${ }^{3}$ vide também FROMMING, 2011).

Além disso, Torop dividiu as traduções em categorias, alegando que toda tradução pode ser total dentro de seus propósitos (critérios de escolha, como vimos) e pode ser de duas maneiras: recodificação (em que o metatexto recebe o código do novo idioma) e transposição (em que o conteúdo é transposto para a nova cultura/língua). Ambas podem ser subdivididas mais uma vez, pois cada uma delas pode priorizar a obra original (análise) ou a tradução (síntese). Por sua vez também cada uma delas pode ainda ser subdividida em: centrada em dominante (destaca um aspecto escolhido pelo tradutor, mas admite outros secundários); ou autônoma (admite apenas um único aspecto na tradução). Isto resulta em 8 categorias de tradução. Quando a importância maior é dada ao código (língua), temos quatro categorias de recodificação, sendo duas voltadas ao original (analítica) e duas à tradução (sintética): recodificação analítica dominante macroestilística (domina a expressão do original, e a estrutura formal se repete no resultado. Conserva o estilo e propõe uma reconstrução global dos elementos estilísticos); recodificação analítica autônoma precisa ("interlinear” ou palavra por palavra, reproduz unicamente a expressão, o código dominante do original. Serve apenas como estudo, não como texto inteligível); recodificação sintética dominante microestilística (reproduz os mecanismos estilísticos próprios do autor); e recodificação sintética autônoma de citação (equivalente à tradução autônoma precisa, onde o tradutor deixa o texto legível; também chamada de “tradução literal”). Quando a importância maior é dada

\footnotetext{
${ }^{2}$ O italiano Bruno Osimo elaborou um curso virtual gratuito sobre tradução e tem uma simpatia pelas teorias semióticas da Escola de Tartu. O curso foi parcialmente traduzido para o português por Mauro Rubens da Silva e Nadia Aparecida Fossa. As ideias de Torop aqui utilizadas vêm principalmente desse material mencionado e de seu livro. As referências são dos capítulos da primeira parte. Disponível em $<$ http://courses.logos.it>. Acesso em 27-ago-2011.

${ }^{3}$ Livro traduzido do original em estônio para o italiano por Bruno Osimo e editado em novembro de 2000 como La traduzione totale. Disponível no site <http://courses.logos.it> e, por não possuir paginação no formato virtual, a numeração se refere à nota anterior ao trecho citado. Baixado em 03mar-2009.
} 
ao conteúdo, temos quatro categorias de transposição, sendo duas focadas no original e duas na tradução: transposição analítica dominante temática (o tema, o conteúdo ganha importância; a estrutura formal é negligenciada, como em um poema que tem métrica, rima e ritmo traduzido em versos livres); transposição analítica autônoma descritiva (prioriza a descrição e abandona completamente a forma, como num poema traduzido em prosa); transposição sintética dominante expressiva (observa a expressão causada no leitor do texto original e tenta repetir essa expressão); e transposição sintética autônoma livre (em que há liberdade total nas escolhas tradutórias, tornandose uma adaptação, distante do texto original) (OSIMO, 2004, 21-23).

$\mathrm{Na}$ tradução, portanto, não só o processo tradutório em si ou as peculiaridades do texto da tradução são relevantes, mas também a função da tradução naquela literatura/cultura que o recebe (LEUVEN-ZWART apud TOROP, 2000, 29).

Mas não basta dominar esses aspectos. Para Torop, todo tradutor precisa ter competência linguística, histórico-cultural, artístico-literária e também comunicativa ou pragmática, e sua eficiência será percebida na escolha correta do método tradutório (TOROP, 2000, 292). Também vogam na escolha do método tradutório o tipo de edição e sua imposição, a projeção literária (escopo e tipo de tradução e poética do tradutor) e a projeção linguística (fatores limitantes: língua, cultura e psicologia; transformação tradutória: culturais e linguísticos) (TOROP, 2000, 417). Por existirem tantas alternativas, nenhuma tradução é igual a outra. Por mais que se tente repetir o seu teor integral, sempre há algo nela que foge ao controle do tradutor.

De posse dessa referência, pretendo fazer uma análise, ainda que superficial, da tradução de Dom Casmurro realizada por Kaufmann. Das oito categorias mencionadas por Torop, podemos excluir sem demandar muita análise a recodificação analítica autônoma precisa, uma vez que não há tradução palavra por palavra. A recodificação de citação, a chamada tradução literal, também não foi adotada, pois no capítulo 1 a expressão "conheço de vista e chapéu” tornou-se "den ich flüchtig kannte" (que eu conhecia de passagem). Na linha seguinte, o narrador diz que o passageiro que sentou ao lado de Dom Casmurro "falou da lua e dos ministros", traduzido como “von Gott und der Welt zu reden” (falou de Deus e do mundo). No capítulo 63, Bentinho tem um sonho sobre um bilhete não premiado de seu vizinho Pádua, que lamenta “[...] provavelmente, a roda andara mal; era impossível que não devesse ter a sorte grande”. Kaufmann diz: "Wahrscheinlich habe sich das Rädchen schlecht gedreht, sonst hätte auf diese Nummer unbedingt das Große Los fallen müssen” (Pelo visto a rodinha girou mal, senão teria que obrigatoriamente ter caído a sorte grande sobre esse número). Isto indica que não houve tradução literal da obra.

Além dessas, a transposição sintética autônoma livre também não ocorre, pois o tradutor se mantém bem perto do original. Não há cortes de capítulos ou passagens significativas; apenas pequenas subtrações de caráter redundante no texto, por exemplo. O texto encontra-se de modo completo na tradução. Não há a abreviação dos fatos, nem a chamada adaptação.

Elimina-se ainda a transposição analítica dominante temática, pois, além do tema na tradução, mantém também a forma: foram mantidos os 148 capítulos e seus respectivos títulos, os parágrafos, os discursos diretos (demarcados por aspas e não por travessão, como é peculiar na escrita alemã).

A recodificação sintética dominante microestilística também está ausente, pois o tradutor não reproduz os mecanismos estilísticos próprios de Machado de Assis. Há momentos em que a ironia e o humor sutil não são repassados, nem o jogo 
de palavras e de sentidos diversos. Ao longo da obra, o tradutor optou por simplificações ou linguagem mais explicativa, chegando a corrigir "imperfeições” do original que talvez fossem propositais. Nessa passagem do capítulo 3, temos elementos suficientes para mostrar isso:

\begin{tabular}{|c|c|}
\hline Original & Tradução \\
\hline $\begin{array}{l}\text { Prima Justina creio que se } \\
\text { levantou e foi ter com ela. Seguiu-se um } \\
\text { alto silêncio, durante o qual estive a pique } \\
\text { de entrar na sala, mas outra força, outra } \\
\text { emoção... Não pude ouvir as palavras que } \\
\text { tio Cosme entrou a dizer. Prima Justina } \\
\text { exortava: "Prima Glória! Prima Glória!". } \\
\text { José Dias desculpava-se: "Se soubesse, } \\
\text { não teria falado, mas falei pela veneração, } \\
\text { pela estima, pelo afeto, para cumprir um } \\
\text { dever amargo, um dever amaríssimo..." }\end{array}$ & $\begin{array}{l}\text { Ich glaube, Base Justina ging zu } \\
\text { ihr. Im Zimmer herrschte absolutes } \\
\text { Stillschweigen, und ich war schon nahe } \\
\text { daran einzutreten, aber eine unsichtbare } \\
\text { Macht hielt mich zurück. Was Onkel } \\
\text { Cosme dann sagte, konnte ich nicht } \\
\text { verstehen. Justina rief beschwichtigend: } \\
\text { »Base Glória, Base Glória!« Und José } \\
\text { Dias enstschuldigte sich: »Wenn ich } \\
\text { geanht hätte, wohin das führt, ich hätte } \\
\text { geschwiegen. Ich habe nur aus Verehrung } \\
\text { gesprochen, aus Verherung, aus Liebe, } \\
\text { um eine bittere Pflicht zu erfüllen, eine } \\
\text { äußerst bittere Pflicht... « }\end{array}$ \\
\hline
\end{tabular}

O que exponho serve apenas para provar a ausência da recodificação microestilística, e não considero isso como erro de tradução, já que segue seus próprios critérios. Já no visual dos dois textos, se percebe o estilo conciso de Machado de Assis, havendo mais caracteres na versão alemã. Além disso, na versão alemã, prima Justina não se levanta; apenas vai ter com a mãe de Bentinho: "Base Justina ging zu ihr” (prima Justina foi até ela). Embora a informação de levantar-se talvez seja irrelevante, o estilo machadiano por vezes introduz ações óbvias, ou informa o leitor sobre detalhes despercebidos. Se prima Justina se levantou, é porque estava sentada. Tal sutileza não foi aproveitada pelo tradutor.

Depois, Machado de Assis atribui uma qualidade ao silêncio, uma mensuração ambígua e incomum: alto. O que seria um “alto silêncio”? À primeira vista, pode parecer a descrição do "tamanho" do silêncio, o que justificaria a versão alemã: “absolutes Stillschweigen” (silêncio absoluto). Porém, há outra leitura possível: uma espécie de hipálage, em que o silêncio tenha um nível de volume elevado, gritando a sua mensagem. O silêncio absoluto na tradução impede uma averbação mental dessa hipálage, pois o silêncio da tradução cala, mas o de Machado fala com Bentinho: um silêncio penetrante gritando tão alto dentro da alma que o impede de ouvir as palavras do tio Cosme. Antes desse silêncio, tudo foi perfeitamente captado por Bentinho. Assim, não se trata de palavras inaudíveis, como sugere a versão alemã, senão um mistério ainda mais intenso, que foge à própria verbalização dessa emoção. Machado de Assis era um escritor que explorava questões da Psicologia, ciência que começava a despontar na época. Neste sentido, ele deixa transparecer a incapacidade de "traduzir" em palavras essa sensação, uma vez que se limita a dizer "outra força, outra emoção...”, usando as reticências tanto para enfatizar esse turbilhão de descobertas que se materializava no adolescente quanto, simultaneamente, o fato de ser detido por essa força quando quis entrar na sala para 
tirar satisfação. Mais uma vez, o tradutor alemão ignora esse pormenor e interfere na ação ao completar o pensamento não expresso por Machado: "eine unsichtbare Macht hielt mich zurück” (uma força invisível me deteve). Tal “correção” desvia do estilo machadiano.

Para corroborar tudo o que se disse até aqui sobre esta parte específica, há uma anáfora na fala de José Dias: "falei pela veneração, pela estima, pelo afeto", parcialmente reproduzida na tradução, porém com uma repetição (ou reduplicação) inexplicável de "veneração": "aus Verehrung gesprochen, aus Verehrung, aus Liebe”. Não se sabe ao certo por que o tradutor reduplicou "aus Verehrung", e omitiu "Wertschätzung" (estima). Seria aceitável caso não houvesse um correspondente em alemão. Desta forma, independentemente de tê-lo feito de forma consciente ou não, o tradutor impõe um microestilo que não condiz com o de Machado de Assis, confirmando que ele não elegeu a recodificação microestilística machadiana.

Quanto à transposição analítica autônoma descritiva, também não se detecta na tradução alemã. Esta categoria prioriza unicamente a descrição e abandona completamente a forma, mas não é o que acontece. O tradutor mantém a estrutura formal, os discursos diretos e indiretos, os parágrafos, os capítulos, enfim, ele atém-se ao original.

Com relação à recodificação analítica dominante macroestilística, esta pode ser detectada, pois o que domina é a expressão do original, e a estrutura formal se repete na tradução. O tradutor conserva o estilo da forma, e parece propor uma reconstrução global dos elementos estilísticos, embora abdique do microestilo machadiano, como vimos. Mas não é a única, uma vez que há preocupação com a síntese.

Por fim, detecta-se a transposição sintética dominante expressiva. Kaufmann observa a expressão causada no leitor do texto original, e tenta repetir essa expressão na tradução, numa espécie de equivalência expressiva (ou equivalência dinâmica, termo usado por Eugene Nida). Não é possível mensurar essa intenção, mas pode ser depreendida de sua leitura. Por exemplo, ao conservar o momento histórico (o tradutor mantém o ano de 1857), ele carrega o seu leitor a um período igual ao do leitor do original. Além disso, outros elementos parecem suportar essa ideia, pois ele conserva as referências geográficas (Petrópolis, Rua de Matacavalos, Engenho Novo, Passeio Público, Itaguaí, Rio de Janeiro), boa parte dos usos e costumes (beijar a mão, saudar o Imperador sem chapéu na cabeça), a cadência no linguajar (leve e popular, como na época), outras referências históricas constantes no texto (contos de Réis, Padre Feijó, Imperador, Papa Pio IX). Também a disposição dos discursos, a trama, os conflitos da época são trabalhados com eficiência, de modo que se perceba uma tentativa de causar a mesma impressão no leitor da tradução.

\section{A traduzibilidade da cultura}

Tendo descoberto a categoria tradutória escolhida, podemos lançar um olhar sobre a traduzibilidade da cultura, a qual, segundo Torop (2000, 292-302) apresenta os seus parâmetros e as respectivas estratégias de tradução. Ao perscrutar a tradução quanto aos aspectos da traduzibilidade, traçarei um comparativo, a fim de detectar as escolhas de Kaufmann. Há aqui também embasamento no resumo feito por Osimo (2004, 32-33).

Se o parâmetro é a "língua”, temos: presença ou ausência de categorias gramaticais; realia (expressão que existe apenas em uma cultura); normas de 
conversação em situações determinadas; associações (conotações peculiares das palavras); imagem do mundo ou grau de precisão de uma língua; discurso dos jargões científicos ou técnicos. As estratégias de tradução possíveis são: nacionalização (naturalização, deixando o texto familiar ao leitor); transnacionalização (mantém-se a cultura original); desnacionalização (manutenção de certos elementos que revelem a origem e causem estranheza); mescla de todas as três. A escolha de Kaufmann foi uma mistura das três estratégias, pois a tradução se torna familiar ao leitor, especialmente em casos de expressões de época; há manutenção da cultura original, notadamente no que tange ao clero e a vida burguesa da cidade do Rio de Janeiro; e conservaram-se certos elementos que revelam a origem e causam estranheza, como o próprio título, os nomes dos logradouros, os nomes dos personagens e seus tratamentos (ele mantém o tratamento "senhora”, “senhor”, “dona”).

No parâmetro "tempo", temos: histórico do autor, dos fatos narrados, do aspecto cultural da narrativa. As estratégias podem ser: arcaização (passado abstrato, inverídico); historicização (passado concreto e autêntico); modernização (o tempo usado é o do tradutor); neutralização (não há percepção do eixo temporal pela neutralização dos marcadores temporais). O tradutor escolheu a historicização, posicionando a trama em um passado concreto, com data claramente expressa.

Quanto ao "espaço", temos o social, o geográfico e o psicológico. As estratégias são: concretização perceptiva: localização (através de tradução comentada); visualização (inserção de elementos gráficos ou visuais); naturalização (espaço familiar para o leitor); exotização (mantém o espaço original); neutralização (não identifica com precisão o espaço). Na tradução, temos a exotização, porque o espaço original é mantido, com os respectivos nomes das ruas e demais logradouros da época. Em nenhum momento fez uso de explicações por notas de rodapé ou de final de texto.

O quesito "texto" compreende: sinais de formulação típica de gênero literário; níveis cronotópicos: topográficos da trama (língua do narrador e da narração), psicológicos (coerência perceptiva da descrição dos fatos, ou seja, aura expressiva do personagem, sua visão de mundo) e metafísicos (léxico do autor e sua visão de mundo); e sistema de meio de expressão (ritmo, repetição, motivos, metáforas e conotações). As estratégias são: Conservação/não-conservação da estrutura (hierarquia de elementos e de níveis); conservação/não-conservação da coerência. A tradução conserva a estrutura, com a hierarquia dos elementos e dos níveis presentes. Na mesma proporção encontra-se a manutenção da coerência. O tradutor não foge da sequência dos fatos, tampouco cria elementos estruturais inexistentes no original.

Referente à "obra”, temos a complementaridade do metatexto: pressuposição da interpretação e da reação dos leitores. São estratégias: versão dos leitores; esclarecimento intratextual; comentários interlineares; comentários especiais ao final; comentários sistemáticos gerais; compensação metatextual. Na tradução, vemos a preocupação com os leitores através de esclarecimentos intratextuais, e por vezes usando a compensação metatextual. No capítulo 48, verbi gratia, temos um "não" exclamado em voz alta por Bentinho “que espantou a minha vizinha”. A vizinha era Capitu, mas o tradutor clareou essa informação ao dizer "daß Capitu erschrocken auffuhr” (que Capitu se assustou). Outro exemplo diz respeito a uma correção de um suposto erro de Machado de Assis. No capítulo 4, Bentinho ouve a conversa escondido, e o texto diz referindo-se a José Dias: "Levantou-se para ir buscar o gamão”. Ele passa por Bentinho (que estava escondido atrás da porta), e o narrador 
nessa passagem descreve o personagem José Dias com cerca de 80 palavras. Após a descrição, o narrador torna a dizer "Levantou-se com o passo vagaroso do costume”, o que se transforma em uma espécie de rebobinação da ação, pois no momento anterior José Dias já havia saído do ambiente; o texto, contudo, retorna a um ponto anterior, fazendo José Dias levantar-se novamente, a fim de descrever o modo de andar. Pode ter sido um mero lapso do escritor. O tradutor considerou um equívoco e excluiu a informação repetida "levantou-se", descrevendo o jeito de andar na passagem pelo corredor: "Sein Gang war langsam und gemessen..." (seu andar era vagaroso e calculado...).

Por fim, há a "manipulação sociopolítica": normas e proibições (editio purificata) e tendenciosidade na manipulação da tradução. As estratégias podem ser: depuração (tendenciosa) dos textos; orientação do texto. $\mathrm{Na}$ tradução, temos a presença da depuração do texto original, nem sempre necessária. A manipulação também aparece em passagens sutis que não interferem no cômputo geral da obra. Como exemplo, destaco duas passagens. Na primeira, do capítulo 41, Bentinho tem a palavra em forma narrada. Está dialogando com sua mãe ainda antes de ir ao seminário. O texto chega ao ponto em que ele diz (na voz do narrador): “e pareceu-me que tinha os olhos úmidos. Disse-lhe que também sentia a nossa separação. Negou que fosse separação”. A leitura não apresenta muita dificuldade. Bentinho é o narrador; portanto o sujeito oculto de "disse-lhe” continua sendo Bentinho falando com sua mãe, dona Glória. Na frase seguinte, quem "negou” foi sua mãe, com quem o narrador estava tendo esse diálogo transcrito em forma de discurso indireto. $\mathrm{O}$ tradutor atribui o primeiro pensamento à mãe de Bentinho ao afirmar "Sie sei über unsere Trennung genauso traurig, sagte sie..." (Ela estaria igualmente triste sobre a nossa separação, ela disse...). Ao dar à dona Glória a fala principal sobre a tristeza da separação, o tradutor acaba atribuindo o choro, a fraqueza, a sensibilidade, a emoção maior como um elemento feminino, subtraindo isso dos homens.

Numa segunda passagem, do capítulo 48, Capitu diz: "Você pode achar outra moça que lhe queira, apaixonar-se por ela e casar”. Nesta fala, outra moça toma a iniciativa de querer Bentinho, que se apaixonaria por ela e com ela casaria. Na versão alemã, encontramos "Du kannst ein anderes Mädchen finden, das du magst, in das du dich verliebst und das du heiratest" (você pode achar uma outra moça, que você queira, pela qual se apaixone e com a qual se case). Aqui Bentinho se torna o protagonista do querer. Em outras palavras: Machado de Assis dá ao elemento feminino uma vontade própria de querer um elemento do sexo masculino; por seu turno, o tradutor coloca toda a questão da escolha sobre o elemento masculino, numa visão tradicional de traços androgênicos.

\section{Considerações finais}

Apesar de todos esses parâmetros e suas estratégias se referirem ao processo tradutório, apesar de todos os critérios de escolha serem cuidadosamente pensados, cabe salientar que, por mais próxima e perfeita que seja uma tradução interlinguística ou intersemiótica, por mais completa que se possa realizá-la, é racional admitir que inevitavelmente ela produzirá o chamado resíduo tradutório desde o seu princípio, quer dizer, parte da mensagem original nunca chegará ao receptor do texto traduzido. Por isso é preciso decidir claramente a estratégia de tradução e determinar os aspectos, ou melhor, os componentes mais característicos que podem ser utilizados e os que podem ser desprezados, a fim de garantir a traduzibilidade do original 
(OSIMO, 2004, 36-37). Somente dessa maneira a tradução poderá ser vista como total e perfeita para os seus propósitos.

Sigfrid Frömming

sigfring@hotmail.com

Doutorando em Estudos da Tradução - UFSC

\section{Referências}

ASSIS, J. M. Machado de. Dom Casmurro. Jaraguá do Sul: Avenida, 2012.

. Dom Casmurro. Tradução de Harry Kaufmann. Frankfurt: Suhrkamp, 1980.

BAKER, Mona. Refraiming conflict in translation. In: BAKER, Mona (Ed.). Critical readings in translation studies. New York \& London: Routledge, 2010, pp. 113-129.

CRONIN, Michael. The cracked looking glass of servants: translation and minority languages in a global age. In: BAKER, Mona (Ed.). Critical readings in translation studies. New York \& London: Routledge, 2010, pp. 247-262.

FROMMING, Sigfrid. Max und Moritz: uma tradução comentada. Cadernos em Literatura e Tradução, vol. 12, 2011, pp. 209-224.

GLEDSON, John. Traduzindo Machado de Assis: "Dona Paula”. Tradução de Luana Ferreira de Freitas. In: GUERINI, A.; FREITAS, L. F. \& COSTA, W. C. (Orgs.). Machado de Assis: tradutor e traduzido. Tubarão: Copiart, 2012.

LARAIA, Roque de Barros. Cultura: um conceito antropológico. 14. ed. Rio de Janeiro: Jorge Zahar, 2001.

OSIMO, Bruno. Curso de tradução. Tradução de Mauro Ramos da Silva e Nádia Aparecida Fossa. Disponível em: <http://courses.logos.it>. Acesso em 16-mai2008.

PAVIS, Patrice. O teatro no cruzamento de culturas. Tradução de Nanci Fernandes. São Paulo: Perspectiva, 2008.

TOROP, Peeter. La traduzione totale. Tradução para o italiano de Bruno Osimo. Modena: Logos via Curtatona, 2000.

VENUTI, Lawrence. Local contingencies: translation and national identities. In: BERMAN, Sandra; WOOD, Michael (Ed.). Nation, language, and the ethics of translation. Princetown: Princetown University Press, 2005, pp. 177-202. 